\title{
HEMEROTECAS MADRILEÑAS Y FUENTES HEMEROGRÁFICAS PARA UN ACERCAMIENTO AL 98 PASADO.
}

\section{NEWSPAPER LIBRARYS OF MADRID AND OTHERS SOURCES FOR AN APPROACH TO THE PAST 98}

\section{AUTOR}

\section{Carlos Dorado}

Doctor en pedagogía. Universidad Autónoma de Barcelona (España)

cdorado43@hotmail.com

\section{RESUMEN}

La prensa es considerada, sin ninguna duda, como una gran fuente de información de los sucesos históricos. Una de las razones por las que se puede considerar la prensa como tal tiene que ver, en gran medida, con el año de 1898, año en el que los periódicos, sujetos a la Ley de Imprenta de 1883, tomó un gran protagonismo en la vida política, militar y social.

\section{PALABRAS CLAVE}

Prensa - 1898 - Gobierno.

\section{ABSTRACT}

The press is concerned, no doubt, a great source of information on historical events. One of the reasons why the press can be considered as such has to do largely with the year 1898, year in the newspapers, subject to the Press Law of 1883, took a leading role in the political, military and social. 


\section{KEY WORDS}

Press - 1898 - Government.

\section{INDICE}

A estas alturas del desarrollo de la historiografía contemporánea la estimación de la prensa como documento primario fundamental, con todas las prevenciones y matizaciones necesarias, está fuera de discusión.

A esta valoración han contribuido decisivamente acontecimientos como los que vivió España en el año crucial de 1898, donde la prensa, arropada en la ley de Imprenta de 1883, asumió un protagonismo fundamental no sólo como testigo y registro del devenir histórico, sino como agente activísimo en el desarrollo de la vida política, militar y, aun, en la psicología nacional. Hasta tal punto que ya en aquellos mismos días se alzaron voces denunciando una gravísima "irresponsabilidad" por parte de los periódicos, capaces de crear en el público lector estados de optimismo o pesimismo, de patrioterismo o depresión, que llegaban a influir en el propio gobierno y en los mandos militares.

Fueron muy acerbas las críticas de los periodistas a Martínez Campos, a Weyler, a los proyectos y al gobierno autonómico coloniales. Hasta el extremo de que, como reacción, las redacciones de algunos periódicos fueron asaltadas y saqueadas por quienes se sintieron agraviados.

Bien es cierto que la propia prensa dio muestras de madurez planteando, en ocasiones, su autocrítica y la consciencia de sus limitaciones y servidumbres, por su parte, a la opinión pública. Algunas periódicos escribían sabiendo de antemano lo 
que los lectores deseaban leer impreso, cultivando el sensacionalismo con planteamiento mercantilista.

Pero también hay que reconocer el acierto y contundencia de la prensa al denunciar la responsabilidad de la corrupción administrativa, de la improvisación y el descuido de la metrópoli frente a los problemas coloniales. Y, sobre todo, en denunciar desde el principio el cinismo, la hipocresía, el determinante intervencionismo belicista de fuertes grupos de prensa norteamericana. La historia del "periodismo amarillo" tiene en el Desastre español uno de sus puntos más vergonzosos y lamentables.

Sobrevenida la contienda - recogida en los periódicos, con fuerte dramatismo y, en ocasiones, con ingenuidad increíble- y cuando la derrota se convirtió en "desastre moral", entre los primer en ser llamados a la petición de responsabilidad fue la prensa, señalada como la "gran culpable" de la catástrofe.

Ahora, sin embargo, vendrá a corresponderle uno de sus períodos más brillantes, al ser receptora de las "consignas de regeneración" lanzadas no sólo por quienes serán conocidos, más o menos arbitrariamente, por "Generación del 98", sino por la inmediatamente anterior, en plena madurez todavía artística y creativa.

En todos los casos, y con rapidez, la prensa había ido despojándose de su valor puramente instrumental para adquirir ya la categoría permanente de documento para la Historia.

Al intentar delimitar, sin embargo, qué prensa puede circunscribirse dentro de un apartado de "prensa del 98" se plantea primordialmente el problema de fijar el marco cronológico.

El conflicto de las colonias residuales, que venía arrastrándose desde la segunda década del siglo XIX, se agudiza sensiblemente con el Sexenio Revolucionario y es 
actualidad permanente desde los intentos reformadores de Maura en 1892 y dramática desde el "grito de Baire" en febrero de 1895.

Por razones prácticas, sin embargo, y a la hora de señalar localizaciones en Hemerotecas, se impone considerar como "Prensa del 98" no sólo a la de ese año sino a los años inmediatamente anterior y posterior.

Es en este capítulo de "Prensa del 98", donde la Hemeroteca Municipal de Madrid, tiene, como tienen otros muchos, motivos para fundamentar la importancia de su fondo documental y el reconocimiento internacional de que goza. La gestación, afloramiento y consecuencias del Desastre puede seguirse a través de las numerosísimas colecciones de prensa, de diversos matices y opiniones, españolas o no, conservadas en ella.

Las colecciones más numerosas son, con mucho, y es lógico, las aparecidas en Madrid. En primer lugar, los grandes diarios de la Restauración que recogieron más o menos objetivamente, la marca de los acontecimientos y lanzaron sus dardos al Gobierno y el Ejército. Precisamente los ataques que contra éste dirigieron El Globo y El Resumen llegó a tal tensión que provocó el asalto a las redacciones de los dos diarios. Dentro de la campaña orquestada contra Martínez Campos, le manifestaron su apoyo El Correo Español y El Progreso.

En las críticas a Weyler se destacó El Nacional. Fue también muy severo El I mparcial, que dio la noticia del hundimiento del Maine ya el día 16 en un extraordinario de la tarde. Otros como La Opinión o La Época publicaron su propia estrategia de guerra, con llamativa simplicidad. El País publicó el Protocolo de Washington, plasmación de la derrota, con una orla negra en toda la portada. También son destacables las denuncias de la actitud norteamericana desde la Época. El Tiempo publicó el célebre artículo de Silvela "Sin pulso". Entre otros diarios madrileños destacados en esas fechas, y también conservados, están: La Correspondencia de España, El Heraldo de 
Madrid, El Liberal, El Correo Militar. No debe ser olvidada la prensa republicana o de izquierda, como El Socialista o la libertaria Revista Blanca, abiertamente opuestos a la guerra. La prensa ilustrada está representada dignísimamente por la Ilustración Española y Americana. Se hicieron célebres las sátiras y caricaturas de El Acabose.

Una relación, en fin, que se haría enfadosamente inacabable. Porque, sólo editados en Madrid, hemos registrado unos ciento cuarenta, de temática diversa, claro es, y muchos de ellos incompletos. Y de los años inmediatamente anteriores o posteriores, aunque no se guarde precisamente el año 1898, unos doscientos.

También la prensa de provincias, que siguió los acontecimientos con no menos interés, está abundantemente representada en nuestras colecciones. En lugar preeminente, la prensa barcelonesa, de la que es preciso destacar El Diario de Barcelona, El Diluvio, el canovista La Dinastía o La Ilustración Artística, que recogerá las crónicas de Emilio Castelar, o la satírica Campana de Gracia.

Por el alcance internacional que alcanzó el conflicto es de interés considerar la posibilidad de compulsar la prensa extranjera.

Numéricamente no es muy abundante el fondo conservado. Pero es innecesario resaltar el interés que ofrece el seguir, más que el curso de los acontecimientos, la forma de presentarlos y comentarlos en el New York Herald o, en lengua española pero también neoyorquinos, Las Novedades, Cuba o Patria. También es posible hacerlo en II Secolo de Milán, el National Zeitung de Berlín, el londinense Times o la Quinzaine de París.

Capítulo aparte merecen, como es natural, los periódicos editados en los escenarios de la contienda. Son numerosas las publicaciones filipinas: Gaceta de Manila, Revista Mercantil, El Comercio, La República Filipina, Diario de Manila, La Independencia, República de Filipinas, etc., o los satíricos Bejuco o Cometa. 
Aunque mucho menos abundante, la prensa cubana del momento cuenta con una importante colección: el entrañable Diario de la Marina, desde 1884 a 940, la Gaceta de la Habana hasta octubre mismo del 98 o la ya libertaria Cuba Libre con un único número del día 4 de diciembre.

El empeño, que legítimamente nos corresponde por destacar las colecciones custodiadas en la Hemeroteca Municipal madrileña no nos hace perder de vista el interés del público investigador de esta etapa histórica por poder localizar esta información periodística.

Hay que consignar, por tanto, que la Biblioteca Nacional de Madrid guarda un considerable fondo de prensa de Madrid y del resto de España, correspondiente a estos años. El Correo Español, La Época, El Día, El Heraldo, La Iberia, El Español, La Izquierda Dinástica, El Globo, La Ilustración Española y Americana, Blanco y Negro, El Liberal, El Nacional, madrileños que allí están. Y una importante colección de periódicos filipinos: El Comercio, Diario de Manila, El Heraldo de la Revolución, La Independencia, La República Filipina, La Voz Española, La Gaceta de Manila, y de Puerto Rico, La Bandera Española y La Correspondencia.

Títulos fundamentales como La Época, El Liberal, El Imparcial, La Ilustración Española y Americana, o Blanco y Negro se guardan en la venerable biblioteca del Ateneo de Madrid.

Y no puede ser obviado el rico fondo de prensa antigua propiedad del Senado, del que no podemos mencionar títulos pormenorizados por no disponer de un catálogo que los recoja con detalle.

Sirvan estas líneas, improvisadas por la premura de tiempo, para subrayar, por más que hacerlo vaya a ser hoy redundante, la importancia de la Prensa como fuente de primer orden para estudiar la sociedad española, agitada en su entraña por los 
dramáticos acontecimientos de 1898, y la posibilidad de compulsar esas publicaciones en diversas instituciones culturales madrileñas, especialmente en la Hemeroteca del Municipio. Aunque, por desgracia, el paso del tiempo -que ya es un siglo- y la frecuencia incesante han afectado, a veces gravemente, estas valiosas reliquias de la comunicación humana, hasta el punto de imponerse, ante la alternativa de una pérdida irreversible, la retirada de algunas colecciones en espera de su restauración y microfilmación sistemática. La mejor de las voluntades está permitiendo superar poco a poco estas penosas limitaciones.

Y nuestra gratitud al profesor D. Enrique Ríos, querido amigo de esta institución, por brindarnos esta oportunidad de esta breve comunicación.

\section{BIBLOGRAFÍA}

- $\quad$ Albert, P.: Historia de la Prensa, Madrid, 1990.

- ANUARIO GUIA de la Prensa Española e Industrias Anexas..., Madrid, 1897.

- $\quad$ ASENJ O, A.: La Prensa madrileña a través de los siglos, Madrid, 1933.

- SÁNCHEZ ARANDA, J. J., BARRERA DEL BARRIO, C.: Historia del periodismo español, Pamplona, 1992.

- GÓMEZ APARICIO, P.: Historia del periodismo español. De las guerras coloniales a la Dictadura, Madrid, 1974

- EL MUNDO de los Periódicos: Anuario de la Prensa Española y Estados Hispanoamericanos... 1898-1899, Madrid, (1898?). 
- PIZARRoso QUINTERO, A.: De la Gazeta Nueva al Canal Plus: Breve Historia de los medios de comunicación en España, Madrid, 1992.

- PIZARROSO QUINTERO, A. (Coordinador): Historia de la prensa, Madrid, 1994.

- SeOANE, Mạ Cruz : Historia del periodismo en España, 2. El siglo XIX, Madrid, 1983.

- $\quad$ TOBAJ AS, M.: El periodismo español (Notas para su historia), Madrid, 1984. 